
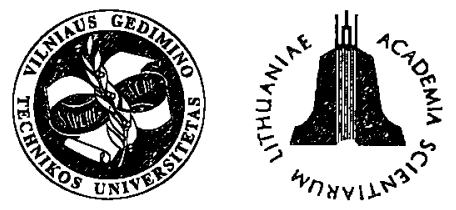

ISSN 1648-4142 TRANSPORT

http:/www.vtu.ltenglish/editions

TRANSPORT - 2003, Vol XVIII, No 2, 72-78

\title{
THE ESTABLISHMENT OF CIRCUMSTANCES AND EVIDENCES OF AN ACCIDENT AND THEIR APPLICTION IN RESEARCH
}

\author{
Arūnas Tautkus ${ }^{1}$, Algirdas Jurkauskas ${ }^{2}$ \\ Kaunas University of Technology, Panevezžys institute, \\ Klaipédos g. 1, LT-5300 Panevėžys, Lithuania \\ Received 20020811 ; accepted 20030228
}

\begin{abstract}
An accident depends on a lot of factors and circumstances. The estabilishment of factors, different evidences and circumstances are very important for research. Some important evidences are fixed when we make photos, do the the measurements of the deformation of means of transport, do the measurements of sliding and of stopping, estimate the condition of road and weather, driver's and pedestrian's actions, do cross-examination of witnesses and so on.

We often have no result even if we know the main circumstances of the accident. So we need some engineer countings for the modelling of various situations.

The method of linear momentum is presented in this article. It is used for the counting of parameters of accidents. The accident diagram gives information for us. We can do the research of an accident with the help of this method and software. So the research into the collision of cars was done with the help of this method and software.
\end{abstract}

Keywords: accident; factors and evidences; linear momentum; speed.

\section{Introduction}

Lawyers looking for recovery often need to employ experts to reconstruct the scene of the accident. Experts try to determine the most probable scenario that led to the accident. Operator or operational factors are the major causes of $90 \%$ of auto accidents. Information including statements, photos, skid marks, roadway factors, laws of physics are used to analyze the dynamics of the collision. The most important evidence will be physical evidence in the form of photos and measurements of the scene often taken by police investigators at the scene in fatal and catastrophic injury cases [1]. A diagram can be constructed showing the impact and rest positions. It is a pity that the police officers, who work at the place of an accident often do not fix the main evidences, which can help to identify the mechanism of an accident. This causes the run of the accident making it more difficult.

\section{Evidences and Factors Causing the Success of Re- search into an Accident}

Types of evidence used by the investigator:

-The accident scene will include a "point of impact" analysis including the preimpact and post impact tire marks

-Photographs that establish the layout and perspective of the scene.

'E-mail: arutaut@takas.lt

${ }^{2}$ E-mail: algirdas.jurkauskas@mf.ktu.lt
-Damaged vehicles.

-Eyewitness testimony: usually the statements are examined for their corroborative value and weighed against the physical evidence.

Factors:

1) Roadway factors; Roadway factors or geometrics refer to the road operating environment. The analysis of a roadway may include: the roadside design, the frictional properties, construction materials, wear, width, crossslope, super-elevation, horizontal and vertical curvature, maintenance, ride quality, average daily traffic, traffic mix, designed use, and structural integrity. Documentation of the roadway environment is crucial in most collision reconstruction cases. Often the roadway itself is a contributing factor in the collision $[2,3]$.

2) Pavement and Shoulder Conditions; Poor pavement and shoulder conditions can play a role in the occurrence of an accident. Bumps, potholes, pavement roughness, and pavement edge drop-off are just a few of the pavement conditions that could cause difficulty for the drivers. There are standard roadway maintenance practices and regulations that departments must abide to create a safe operating environment.

3) Friction Evaluation; Friction is the resisting force of motion between two surfaces when they are in contact. The friction generated between any two surfaces is important in reconstruction since friction converts kinetic energy to heat, noise and deformation and damage of materials. Friction analysis can determine the speed of a car. In most car accident cases the friction is between the roadway and the tire, however it is also present in metal 
to pavement contact, and metal to soil contact in rollover collisions and in motorcycle pre- and post- impact trajectories.

4) Weather Conditions; Uusually found in the police report these can be verified from local newspapers and weather services. A record of these conditions helps to establish whether slippery or wet roads affected the accident. Road conditions are critical in establishing the drag and speed at the time of the accident.

5) Lighting Conditions; Lighting is the most important issue involving accidents at night. Many people overestimate their seeing ability at night and very often the headlights are insufficient to reveal potential collisions in time for the operator to avoid them. The materials used in the construction of roadway surfaces often reflect light in different ways. The road surface has a significant effect on the drivers' recognition of objects and vehicles on the road. Ambient lighting, headlights, moisture conditions and other factors make up a complex set of conditions that determine whether an object or roadway geometry is visible. Pedestrians are often hit at night because the road is not adequately lit or the victim is wearing dark clothing. In this cases it can be determined that the driver could not have seen the pedestrian until it was too late. A pedestrian can often see the car, while the operator cannot see him.

The previous material shows that an accident is caused by lots of factors and circumstances. It is very important to identify the circumstances and factors, which cause the run of research objectivity. The main parameters of an accident are fixed in the diagram in Fig 1.

\section{Linear Momentum Analysis}

As the sources of literature [4] indicate one of the most important parameters that should be determined at the period of car crash investigation is the speed of cars before crash.

One of the methods of speed determination before crashes is the method of linear momentum. We can calculate pre-impact velocities and collision speed changes from the accident scene data and the principle of conservation of linear momentum.

For practical purposes in accident reconstruction, linear momentum can be defined as the vehicle weight multiplied by the vehicle speed in a certain direction. The basic premise of a momentum analysis is based on the law of conservation of moment which can be stated that

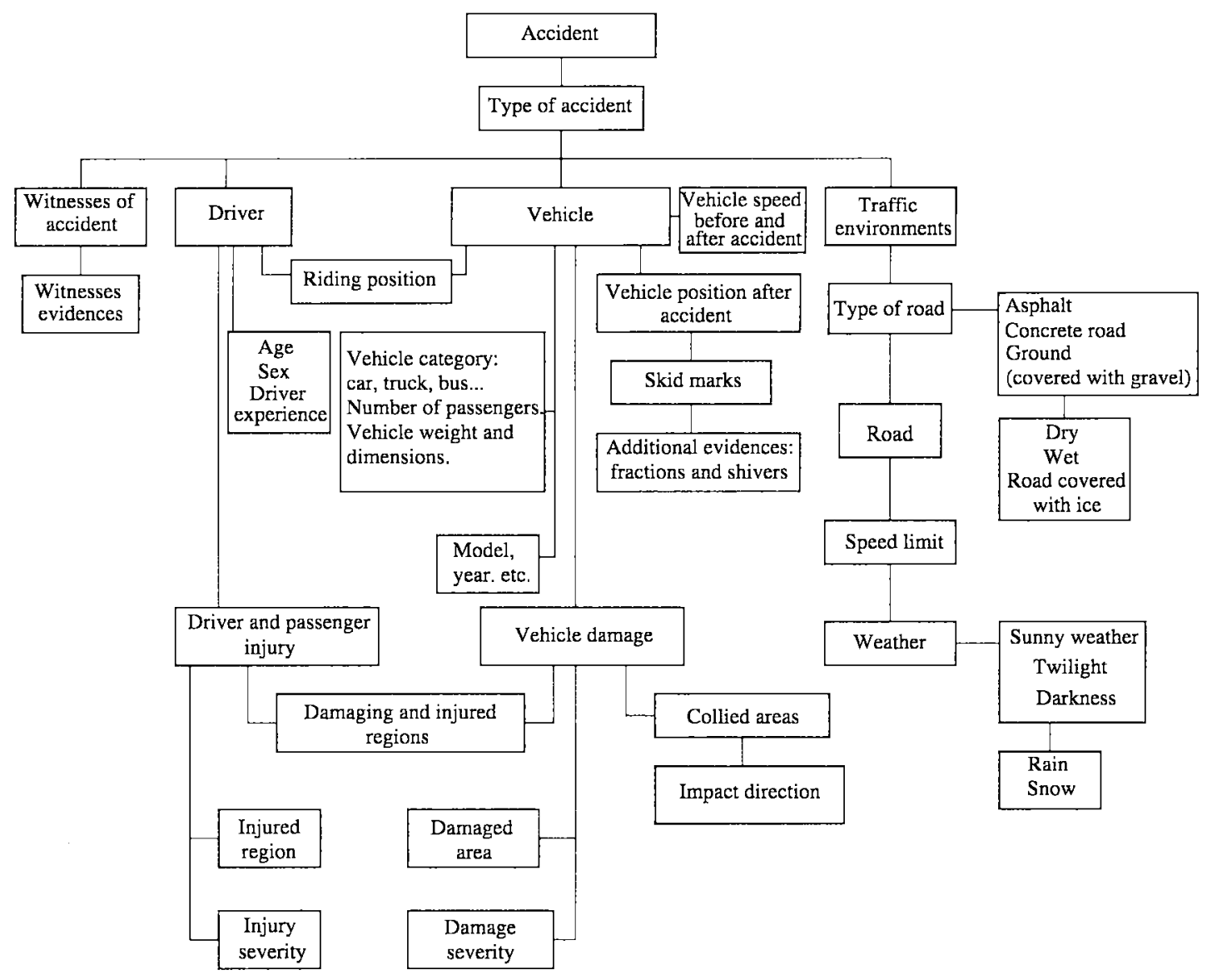

Fig 1. Scheme of accident investigation 
in a group of objects which act upon each other, the total linear momentum immediately following a collision is equal to the total linear momentum immediately preceding a collision. Any moment lost by one vehicle is gained by the other.

Since each vehicle has the weight, speed, and the direction going into the collision, and the weight, speed, and the direction coming out of the collision, there are 12 numerical values associated with the two vehicles. A momentum analysis will solve any two of 12 . The other ten must be evaluated or assumed.

The typical linear momentum analysis has the following phases:

1. The accident reconstructionist must obtain the weight of the vehicles. If actual weighing is not practical, published specifications can be used and an estimate of the weight of the vehicle occupants and contents is made.

2. The impact location and rest position of the vehicles must be determined as part of the collision analysis.

3. The post impact direction is obtained from the physical evidence, such as tire marks and gouges at the collision site or the general direction from impact to rest.

4. The decelerations from impact to rest are evaluated from the post impact braking, rotation, terrain, and contact with such objects as poles, brush and etc.

5. The post impact speeds can then be determined from the evaluated decelerations and the travel distance to rest.

6. At this point, if the pre impact direction for both vehicles is known, the momentum equations can be solved to yield the speed for each vehicle.

7. Alternatively, if the incoming speed and direction for one vehicle is known, the speed and direction for the second can be calculated.

8. The final portion of the analysis involves braking or skidmark length, and takes into account any pre impact deceleration.

Collision events where the momentum analysis has limited or no applicability include:

1. Head or rear end collisions. (In these cases the analysis reduces to one dimension and can only solve one unknown speed or direction.)

2. Collisions with fixed or very heavy objects.

3. Collisions where deceleration values can not reasonably be determined.

Collisions, such as sideswipe of a trailer, in which common velocity is not reached.

\section{Methodology}

Conservation of linear momentum is a direct result of Newton's three laws. It assumes that the only forces that act on the vehicle during the collision are the collision forces. In other words, the collision is assumed to be sufficiently violent that the tire forces are negligible compared with the collision forces. This will not be true in minor collisions with little or no damage.

Write Newton's second law for vehicle one and two [5]:

$$
F_{1} \Delta t=m_{1} \Delta V_{1}
$$

and

$$
F_{2} \Delta t=m_{2} \Delta V_{2} .
$$

By the third Newton's law $F_{2}=-F_{1}$, adding the two equations gives:

$$
m_{1} \Delta V_{1}+m_{2} \Delta V_{2}=0 \text {. }
$$

The above equation can be writen using the definitions in equations 1 and 2 as:

$$
M_{1}+M_{2}=M_{3}+M_{4} \text {. }
$$

This is a vector relationship which states that the total momentum before the collision, $M_{1}+M_{2}$, is equal to the momentum after the collision, $M_{3}+M_{4}$.

The momentum of vehicle one before collision $M_{1}$ is defined as:

$$
M_{1}=m_{1} V_{1} \psi_{1}, M_{2}=m_{2} V_{2} \psi_{2},
$$

where:

$m_{1}, m_{2}$ - weights of vehicles one and two in $\mathrm{kg}$;

$V_{1}, V_{2}$ - entry speeds of vehicles one and two in $\mathrm{km} / \mathrm{h}$; $\psi_{1}, \psi_{2}$-entry angles of vehicles one and two in degrees.

The single vehicle momentum diagram is shown in Fig 2.

The direction of entry speed vector $V_{1}$ and collision force $F_{C}$ is in one line.

Equation (4) is general momentum equation. This can be written as two component equations in the $\mathrm{x}$ and $\mathrm{y}$ directions as:

$$
\begin{aligned}
& M_{1 x}+M_{2 x}=M_{3 x}+M_{4 x}, \\
& M_{1 y}+M_{2 y}=M_{3 y}+M_{4 y},
\end{aligned}
$$

where:

$$
M_{1 x}=m_{1} V_{1} \cos \psi_{1}, M_{2 x}=m_{2} V_{2} \cos \psi_{2}
$$

and $M_{1 y}=m_{1} V_{1} \sin \psi_{1}, M_{2 y}=m_{2} V_{2} \sin \psi_{2}$. After collision:

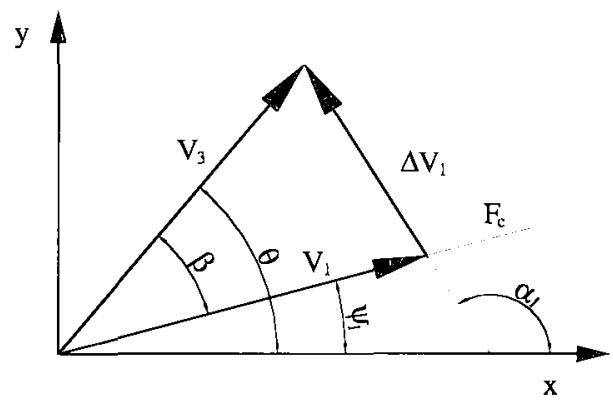

Fig 2. The single vehicle momentum diagram 
$V_{3}$ and $V_{4}$ - departure speeds of vehicles one and two; $\theta$ and $\phi$-departure angles of vehicles one and two.

$V_{3}$ and $\theta$ together define vector $V_{3}$ which is the departure velocity of vehicle one.

$$
M_{3}=m_{1} V_{3} \theta,
$$

projections to axis:

$$
M_{3 x}=m_{1} V_{3} \cos \theta, M_{3 y}=m_{1} V_{3} \sin \theta ;
$$

$V_{4}$ and $\phi$ together define vector $V_{4}$ which is the departure velocity of vehicle two.

$$
M_{4}=m_{2} V_{4} \phi,
$$

projections to axis:

$$
M_{4 x}=m_{2} V_{4} \cos \phi, M_{4 y}=m_{2} V_{4} \sin \phi .
$$

From the equations (4)-(8) it can be written:

$m_{1} V_{1} \cos \psi_{1}+m_{2} V_{2} \cos \psi_{2}=m_{1} V_{3} \cos \theta+m_{2} V_{4} \cos \phi(9)$

and

$m_{1} V_{1} \sin \psi_{1}+m_{2} V_{2} \sin \psi_{2}=m_{1} V_{3} \sin \theta+m_{2} V_{4} \sin \phi .(10)$

These two equations can be used to eliminate $V_{1}$ and solve for $V_{2}$.

Solve for $V_{1}$ in equation (10)as:

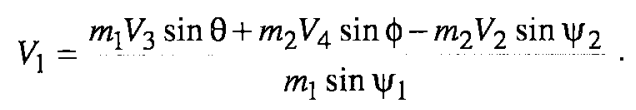

Substitution of equations (11) into equation (9) and collecting the $V_{2}$. terms to the left and the others to the right gives:

$$
\begin{aligned}
& V_{2} m_{2}\left[\cos \psi_{2}-\sin \psi_{2} \frac{\cos \psi_{1}}{\sin \psi_{1}}\right]=V_{3} m_{1}\left[\cos \theta-\sin \theta \frac{\cos \psi_{1}}{\sin \psi_{1}}\right]+ \\
& V_{4} m_{2}\left[\cos \phi-\sin \phi \frac{\cos \psi_{1}}{\sin \psi_{1}}\right]
\end{aligned}
$$

Multiplying through by $\sin \psi_{1}$ and isolating $V_{2}$ to the left gives:

$$
V_{2}=\frac{m_{1} V_{3}\left[\cos \theta \sin \psi_{1}-\sin \theta \cos \psi_{1}\right]+m_{2} V_{4}\left[\cos \phi \sin \psi_{1}-\sin \phi \cos \psi_{1}\right]}{m_{2}\left[\cos \psi_{2} \sin \psi_{1}-\sin \psi_{2} \cos \psi_{1}\right]} .
$$

Once $V_{2}$ is found and $V_{1}$ can be solved from equation (11) or equation (9) can be rearanged as:

$V_{1}=\frac{m_{1} V_{3} \cos \theta+m_{2} V_{4} \cos \phi-m_{2} V_{2} \cos \psi_{2}}{m_{1} \cos \psi_{1}}$.

The collision speed changes $\Delta \mathrm{V}_{1}$ and $\Delta \mathrm{V}_{2}$ we can calculate too. The law of cosines is used to determine the magnitude of $\Delta \mathrm{V}_{1}$ and then the force angle $\alpha_{1}$ is calculated from components along the $x$ axis. (look Fig 2)

The law of cosines gives the following relation:

$$
\Delta V^{2}{ }_{1}=V_{1}{ }^{2}+V_{3}{ }^{2}-2 V_{1} V_{3} \cos \beta \text {. }
$$

Substituting $\beta=\theta-\psi_{1}$ gives:

$$
\Delta V_{1}=\sqrt{V_{1}^{2}+V_{3}^{2}-2 V_{1} V_{3} \cos \left(\theta-\psi_{1}\right)} .
$$

The angle of speed change vector can be determined from the $\mathrm{x}$ axis components of the vectors:

$$
V_{1 x}+\Delta V_{1 x}=V_{3 x}
$$

or

$$
V_{1} \cos \psi_{1}+\Delta V_{1} \cos \alpha_{1}=V_{3} \cos \theta .
$$

Isolating $\alpha_{1}$ gives:

$$
\alpha_{1}=\cos ^{-1}\left[\frac{V_{3} \cos \theta-\cos \psi_{1}}{\Delta V_{1}}\right] \text {. }
$$

Now $\Delta V_{1}$ and $\Delta V_{2}$ can be determined from conservation of momentum equation rewritten as:

$$
\begin{aligned}
& m_{1} \Delta V_{1}=-m_{2} \Delta V_{2}, \\
& \Delta V_{2}=\frac{m_{1}}{m_{2}} \Delta V_{1} .
\end{aligned}
$$

The force angle $\alpha_{2}$ is opposite to that applied to the first vehicle and is defined by the equation:

$$
\alpha_{2}=\alpha_{1}+180^{\circ} \text {. }
$$

The linear momentum equations (3) - (19) do not give any soliution if approach angles of the two vehicles are the same or $180^{\circ} \mathrm{C}$. For this case we can use the method which is indicate in [6].

For an inline solution, one of the vehicle entry speeds must be specified. The departure directions and other entry angle is adjusted to the entry angle of the specified vehicle. The departure speeds are not adjusted. As an example, suppose the speed and direction of vehicle one are known. Therefore, $m_{1}, m_{2}, V_{1}, \psi_{1}, \psi_{2}, V_{3}, \theta, V_{4}$ and $\phi$ are all known. Then the total momentum, $\sum M$, after collision can be written:

$$
\sum M=M_{3}+M_{4}
$$

or

$$
\sum M=m_{1} V_{3} \cos \left(\psi_{1}-\theta\right)+m_{2} V_{4} \cos \left(\psi_{1}-\phi\right) .
$$

The entry momentum of the second vehicle will then be found from assessing the total momentum before the collision:

$$
M_{2}=m_{2} V_{2}=\sum M-m_{1} V_{1}
$$

and

$$
V_{2}=\frac{\sum M-m_{2} V_{1}}{m_{2}}
$$

A similar equation can be derived if $V_{2}$ and $\psi_{2}$ are known and then we can calculate $V_{1}$. 


\section{Counting of Tipical Accident Parameters Using the Method of Linear Momentum}

The computer programme "Crash" was made using the method which is presented in chapter 3 . We can identify lots of parameters of an accident such as: angular and inline speeds of means of transport, the changes of speeds, the angle of collision and others, when we use the programme "Crash" and know the place of means of transport and the place of collision at the moment of the accident. The experts, who research the accidents, have the problem, because the parameters are very various.

So we have to create the methodologies for different groups of parameters and for tipical accidents. We can use this metodologies for counting of parameters of another accidents later.

Also we can do the research of parameters of tipical accidents using the "Crash". In some cases, for example, when we have the frontal collision this material can be used with some exceptions. Chapter 4 presents this.

The research of common accidents is described in this article (there are about $13 \%$ of these accidents) [7].

The diagram of linear momentum and the scheme of such situations are given in Fig 3.

One of the main questions, which the experts have to answer, is the speed of cars before an accident [1]. We paid great attention to this parameter during the research.

When we do the research of the place of an accident it is very important to fix the type of pavement and its state very precisely. It causes the interaction between wheels of a car and pavement and at the same time it causes the parameters of an accident too. Some countings were done and some dependences of speed were identified using the statistic data [3] when the pavement of roads is different (Fig 4-7).
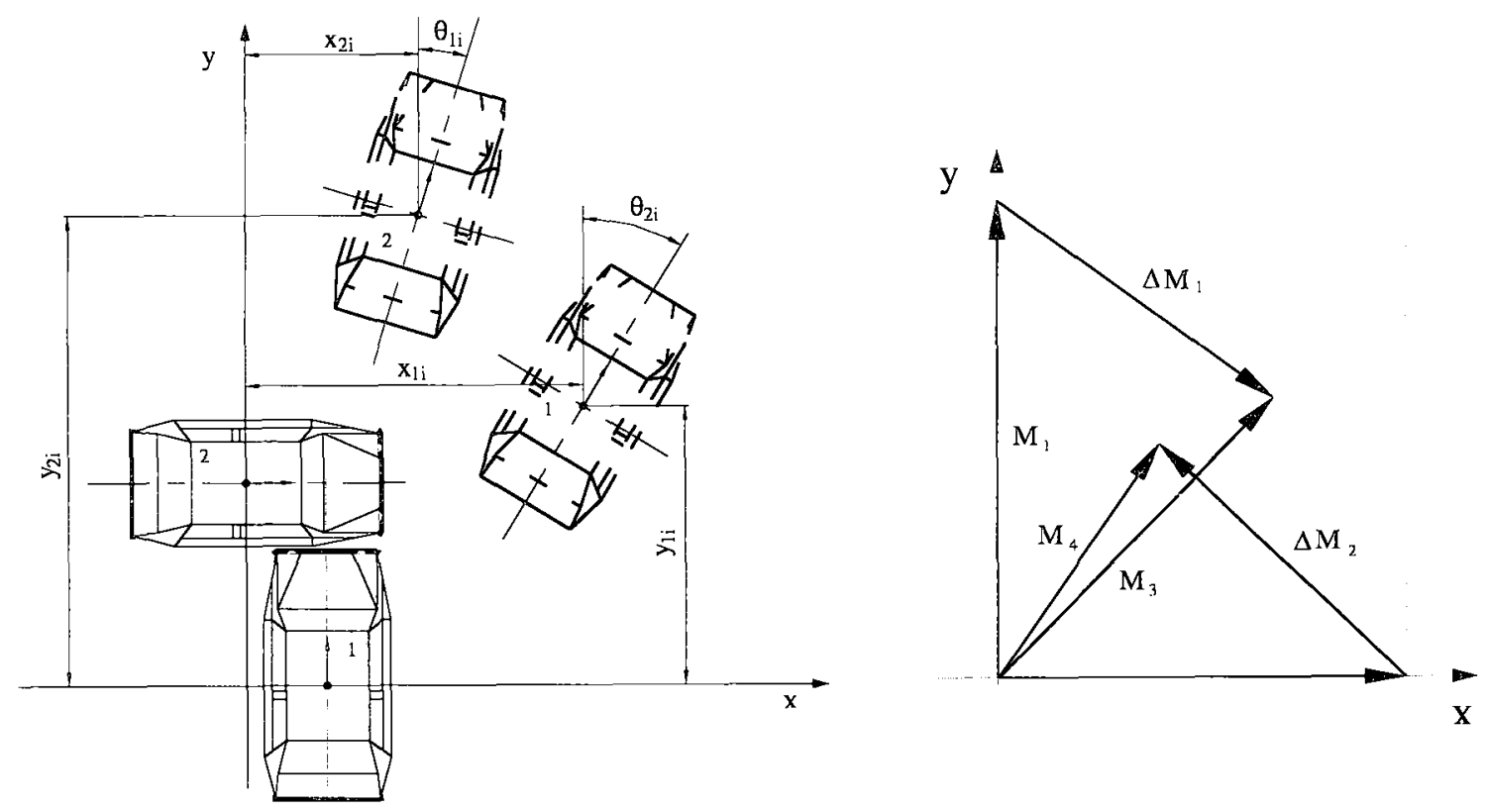

Fig 3. Scheme of side collision and linear momentum diagram

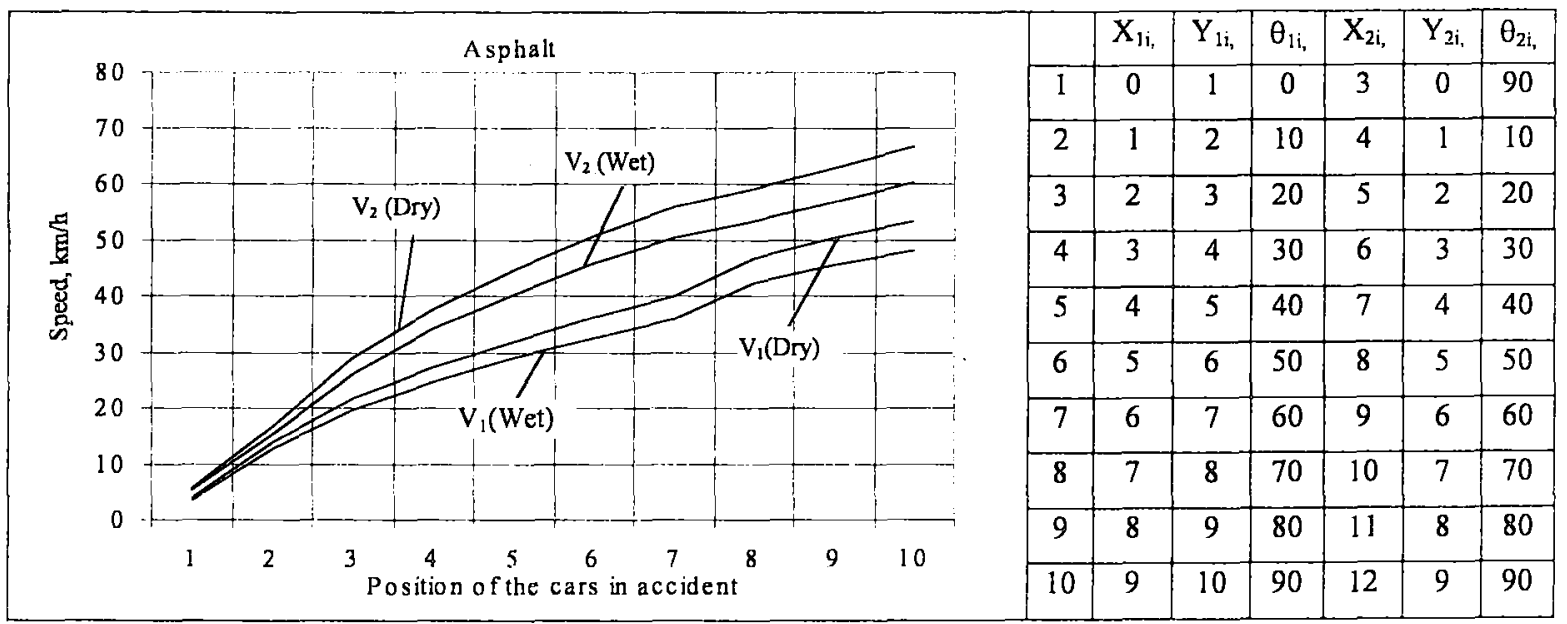

Fig 4. The dependence of speed upon the state of means of transport on asphalt pavement during an accident 


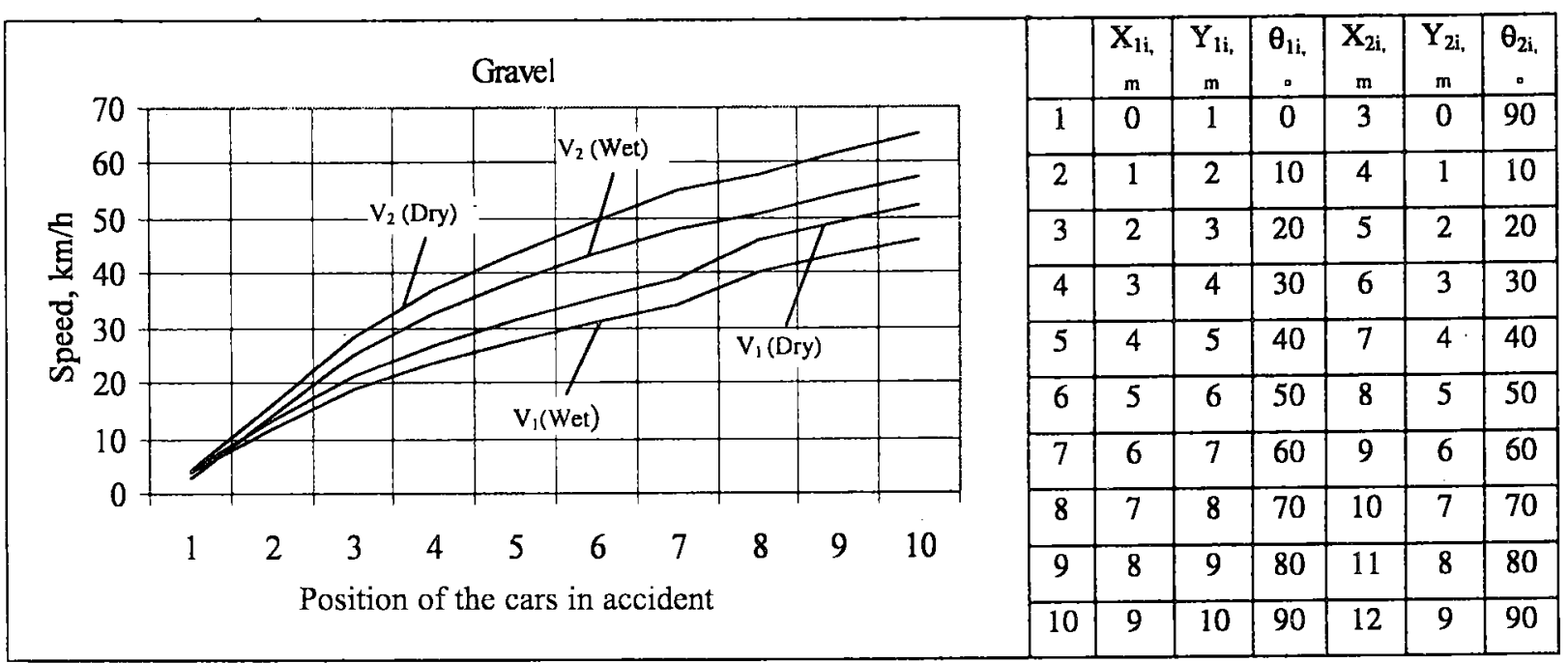

Fig. 5 The dependence of speed upon state of means of transportation on gravel pavement during an accident

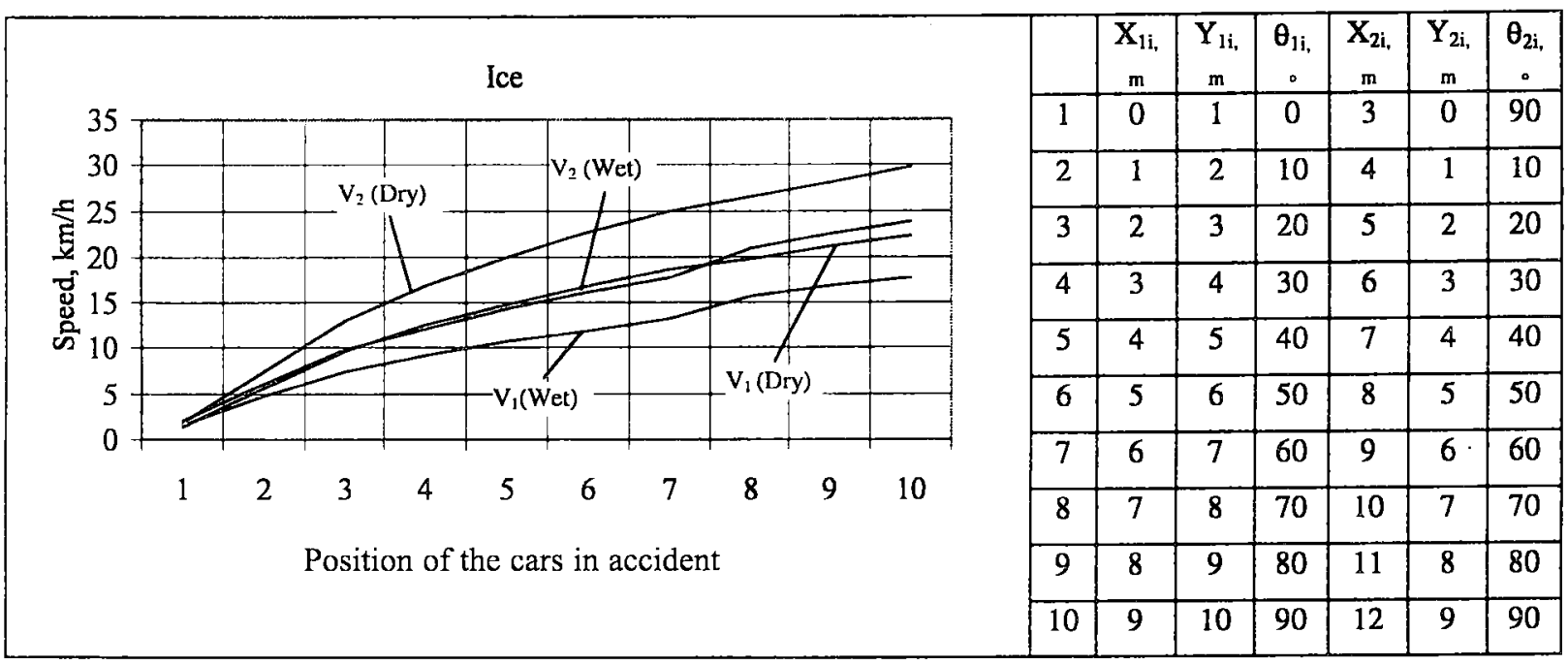

Fig 6. The dependence of speed upon state of means of transportation on snow pavement during an accident

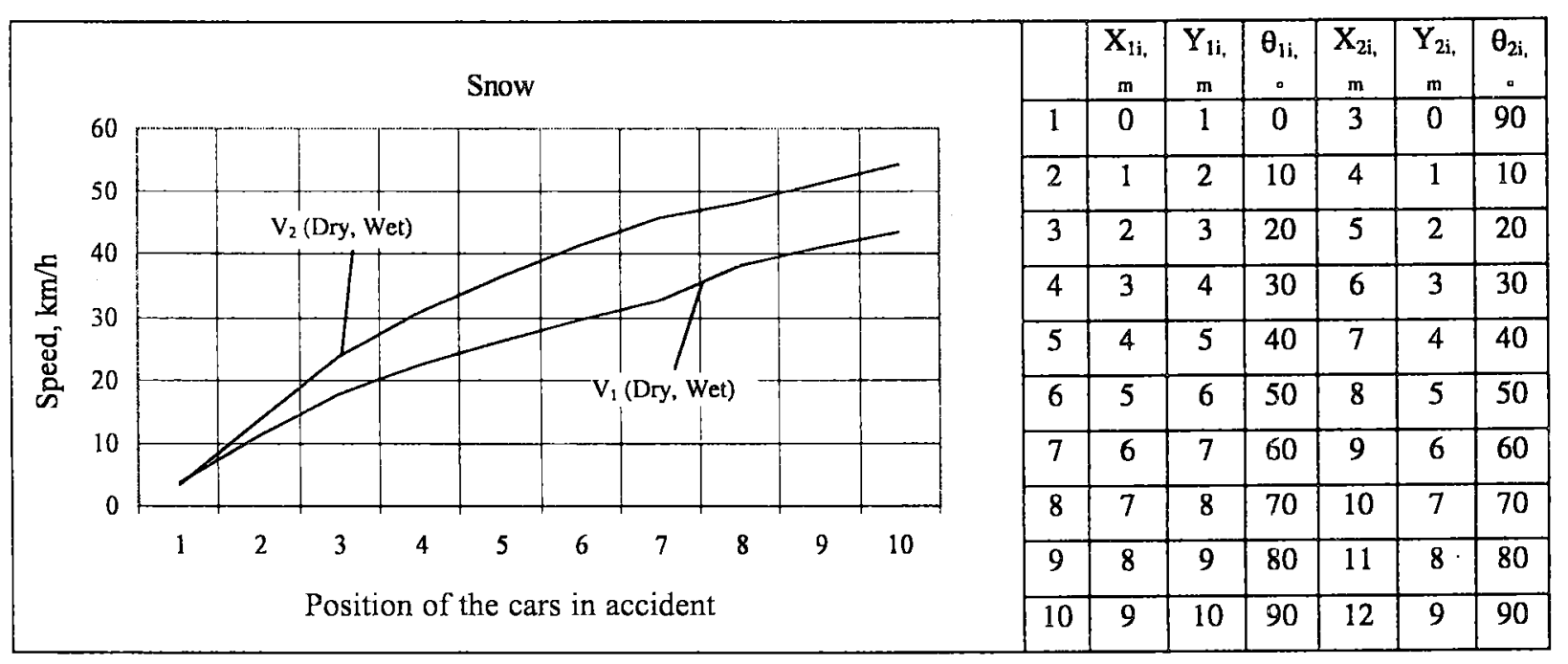

Fig 7. The dependence of speed upon the state of means of transportat on ice pavement during an accident 


\section{Conclusions}

1. We can determine the speed of cars and other parameters using the article methodology at the moment of accident. We need to fix the position of cars and the place of the collision after the accident as precisely as posible because it is necessary for this purpose. When we do the specific countings the results depend on primary information from the place of an accident, i. e. they depend on the accuracy of a diagram.

2. The movement of cars and the position after the collision depend on the pavement and the state of road. When we have different pavements and states of roads the cars can get at the same place after the accident, but they have different speed at the moment of an accident. The dependencies which are given show that.

3. When we go farther into the distance from the place of the collision the speed of cars is bigger at the moment of the accident. The dependencies which are given show that. The speed of the first and the second car on dry and wet asphalt differs from the same cars on ice about $50 \%$ when the cars are at the same position after the accident.

4. Acording to the position of cars after the accident on the road which is covered with dry and wet snow the dependencies of speeds are the same, but the coefficient of friction differs [6].

5. The speed should be equal to zero when the place of the collision and the position of cars after the accident are the same. After some countings we can see that the smallest speed of cars remains at the same place (at the place of an accident) and it is $3-5 \mathrm{~km} / \mathrm{h}$.

\section{References}

1. Tautkus, A.; Jurkauskas, A. Evaluation of car crash parameters in the case of collision. Transport (Transportas). Vilnius: Technika, 2002, XVII t., No 3, p. 91-95.

2. Tautkus, A.; Jurkauskas, A. Dynamics investigation of motion of transport after accident (Transporto priemoniu poavarinio judejimo dinamikos tyrimas). In: Mechanika2000. Proceedings of the International Conference. Kaunas: Technologija, p 272-276 (in Lithuanian).

3. Warner, C. Y.; Smith, G. C.; James, M. B.; Germane, G. J. Friction aplications in accident reconstruction. SAE Paper \#830612 Collision Safety Engineering, Inc. Orem, UT. Presented at International Congress and Exposition, Detroit, MI, February 1983.

4. Steve Otto, Samuel T. Ariaratnam Analysis of Road Surface Profiles. Jourral of Transportation Engineering, 1999, Vol 125, issue, p. 55-59.

5. Milton, J. and Mannering, F. The relationship among highway geometrics, traffic-related elements and motor-vehicle accident frequencies. Transportation, 1998, Vol 4, p. 395 413.

6. Koshiro, Ono and Munekazu, Kanno. Influences of the physical parameters on the risk to neck injuries in low impact speed rear-end collisions, Accident Analysis \& Prevention, Vol 28, Issue 4, July 1996, p. 493-499.

7. Ilarionov, V. A. Examination of car accidents (Исследования автодорожных происшествий). Moscow: MADI, 1989. 240 p. (in Russian). 